\title{
Finite Element Analysis of WWCB WALL Panel Flexural Behaviour
}

\author{
Mst. Sadia Mahzabin, R. Hamid, W. H. W. Badaruzzaman \\ Department of Civil \& Structural Engineering, Universiti Kebangsaan Malaysia, Bangi, 43000, Selangor, Malaysia \\ E-mail:lira01026@yahoo.com,roszilah@vlsi.eng.ukm.my,whamidon@vlsi.eng.ukm.my
}

\begin{abstract}
In the present work, the finite element method is applied to understand the load-deflection response of Wood Wool Cement Board (WWCB) wall panel. The WWCB wall panel was modelled using ANSYS finite element software with 8-noded SOLID65 and SOLID45 Element. The same parameters as the experimental data were used to model the wall panel in FEA. Characteristic points on the load-deflection response curve predicted using finite element analysis (FEA) were compared to experimental data. The comparison shows that the ANSYS finite element program is capable of modelling and predicting the actual deformation behaviour for wall panels. Conclusions were then made as to the accuracy of using finite element modelling for analysis of WWCB wall panel.
\end{abstract}

Keywords - ANSYS; WWCB; load-deflection; Finite element analysis.

\section{INTRODUCTION}

The use of FEA has been the preferred method to study the behaviour of WWCB wall panel for economic reasons. By understanding the use of finite element method, more efficient and better analysis can be made to fully understand the response of individual structural components and their contribution to a structure as a whole. Monique and Harry (2002) contained a paper concerning FEA of wood frame shear walls. They evaluated the effect of vertical load on the static and cyclic behaviour of the wood frame shear walls and their results shown good correlation between FEA and experimental data. Tavio and Tata (2009) developed a nonlinear finite element modelling of rectangular normal strength reinforced concrete columns under axial compressive loading. Their results indicate that the stressstrain relationships obtained from the analytical model using ANSYS are in good agreement with the experimental data.

Aainaa (2008) proposed a method to determine the ultimate load of the WWCB wall panel and type of failure occurred using experimental works. The experimental ultimate load determined was $83.3 \mathrm{KN}$. The FEA calibration study included modelling a wall panel with the dimension and properties corresponding to WWCB wall panel tested by Aainaa (2008).

The objective of this paper was to investigate and evaluate the use of the finite element method for the analysis of WWCB wall panel. First, a thesis (Aainaa 2008) was conducted to evaluate experimental and analytical procedures related to WWCB components. Second, a calibration model using a commercial finite element analysis (ANSYS) was set up and evaluates using experimental data.

\section{FINITE ELEMENT ANALYSIS}

One of the suitable software that can be utilized to describe the actual failure behaviour of WWCB wall panel is ANSYS. To create the finite element model in ANSYS there are multiple tasks that have to be completed for the model to run properly.

\section{A. Element Type}

The SOLID65 element was used to model the wall panel. This element has eight nodes with three degrees of freedom at each node translations in the nodal $\mathrm{x}, \mathrm{y}$ and $\mathrm{z}$ direction. This element is capable of plastic deformation, cracking in three orthogonal directions and crushing. A SOLID45 element was used for steel plate at the supports for the wall panel. This element has eight nodes with three degrees of freedoms at each node. The geometry and node locations for SOLID65 and SOLID45 elements are shown in figure 1.

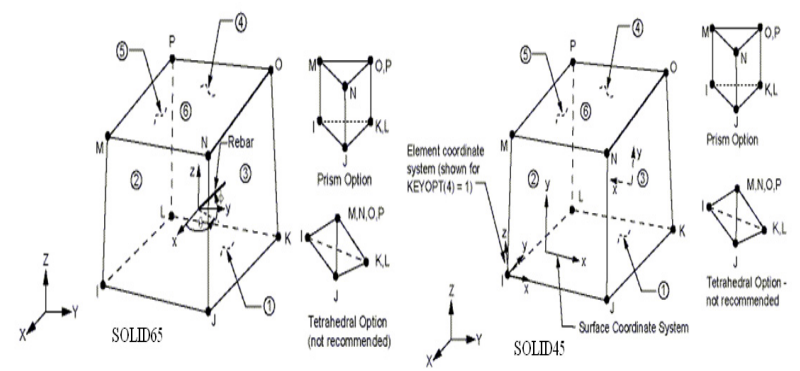

Fig. 1 SOLID65 and SOLID45 geometry 


\section{B. Material Properties and Model}

The SOLID65 element requires linear isotropic and multilinear isotropic material properties to properly model the panel. The multilinear isotopic material uses the von Mises failure criterion along with the Willam and warnke (1974) model to define the failure of the concrete. The modulus of elasticity of the WWCB is $2700 \mathrm{MPa}$ and the Poisson's ratio is 0.3 . The compressive uniaxial stress-strain relationship for the model was obtained from Werasak and Meng (2008) model for light weight concrete used in ANSYS. The SOLID45 element is being used for the steel plates at loading point and supports on the panel. Therefore, this element is modelled as a linear isotropic element with a modulus of elasticity $210 \mathrm{GPa}$ and Poisson's ratio 0.3 .

The panel, plate and supports were modelled as volumes. The model is $2000 \mathrm{~mm}$ long with a cross section of $600 \mathrm{~mm} \times$ $100 \mathrm{~mm}$. The dimensions for the WWCB wall panel are shown in table 1 . The zero values for the $\mathrm{z}$-coordinates coincide with the centre of the cross-section for the wall panel. The combined volumes dimensions of the plate, supports and panel are shown in figure 2 .

TABLE I

Dimensions For Wall Panel, SteEl Plate AND SteEl Support

\begin{tabular}{|c|c|c|c|c|c|c|c|c|}
\hline \multirow{2}{*}{ ANSYS } & \multicolumn{2}{|c|}{$\begin{array}{c}\text { Wall } \\
\text { Panel } \\
(\boldsymbol{m m})\end{array}$} & \multicolumn{2}{|c|}{$\begin{array}{c}\text { Steel Plate } \\
(\boldsymbol{m m})\end{array}$} & \multicolumn{4}{|c|}{ Steel Support (mm) } \\
\cline { 5 - 9 } & & \multicolumn{2}{|c|}{1} & \multicolumn{2}{|c|}{2} \\
\hline $\begin{array}{c}\text { X1, X2 x- } \\
\text { coordinates }\end{array}$ & 0 & 2000 & 800 & 1000 & 100 & 300 & 1700 & 1900 \\
\hline $\begin{array}{c}\text { Y1, Y2 y- } \\
\text { coordinates }\end{array}$ & 0 & 600 & 600 & 700 & 0 & - & 0 & -100 \\
\hline $\begin{array}{c}\text { Z1, Z2 z- } \\
\text { coordinates }\end{array}$ & 0 & 100 & 0 & 100 & 0 & 100 & 0 & 100 \\
\hline
\end{tabular}

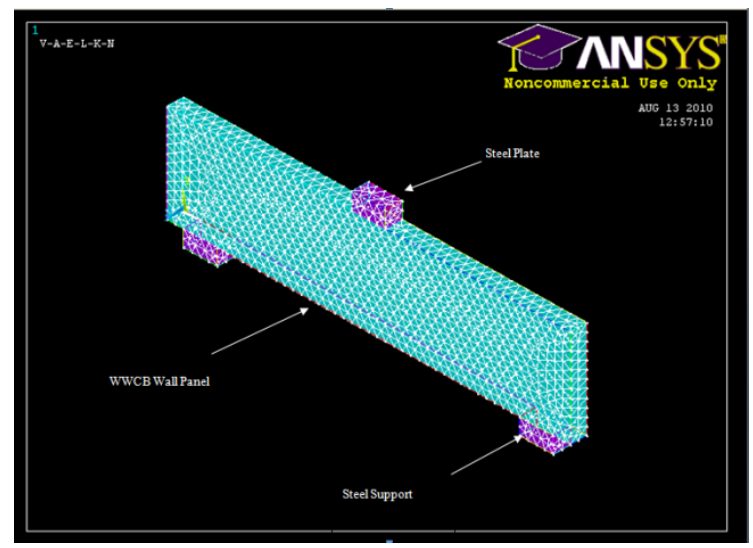

Fig. 2 Volumes with mesh created in ANSYS

\section{Load and Boundary Conditions}

Displacement boundary conditions are needed to constrain the model to get a unique solution. To ensure that the model acts as same as the experimental wall, boundary conditions need to be applied at points of symmetry, and where the supports and loading exist. The support was modelled in such a way that the roller and hinge were created. The ultimate load from experimental data is applied at the steel plate across the entire centreline of the plate. Figure 3 illustrates the panel and applied loading.

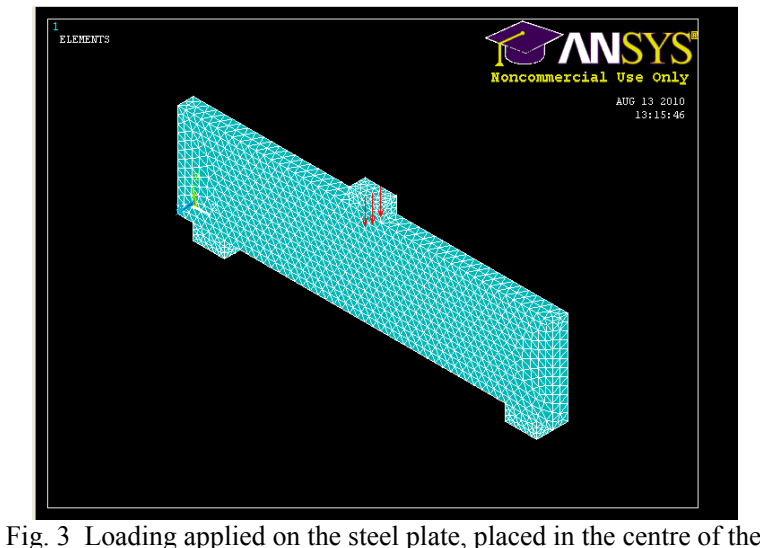
panel

\section{COMPARISON OF ANALYTICAL AND EXPERIMENTAL RESULTS}

The finite element analysis of the model was set up to examine the behaviour of cracking and strength limit state of the panel. The Newton-Raphson method of analysis was used to compute the nonlinear response.

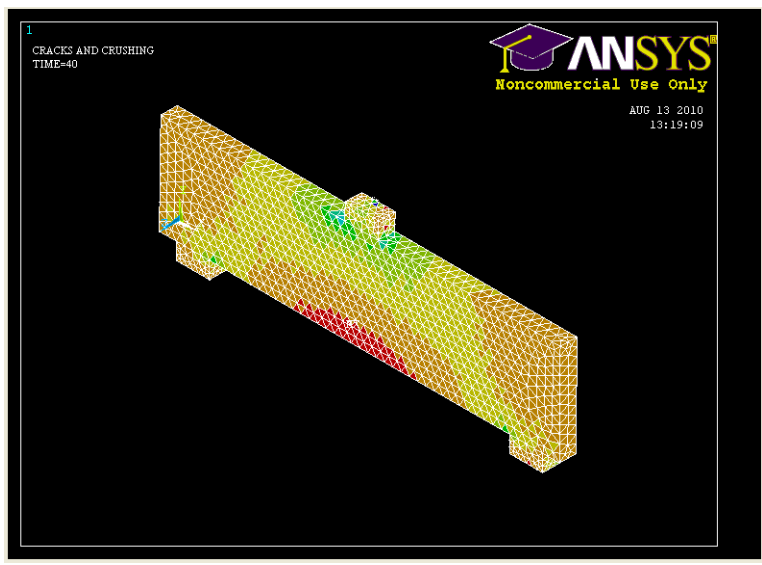

Fig. 4 Increase cracking at the wall panel

In the non-linear region of the response, subsequent cracking occurs as more loads are applied to the panel. This cracking can be seen in figure 4 . At load $80 \mathrm{KN}$, the panel no longer can support additional load.

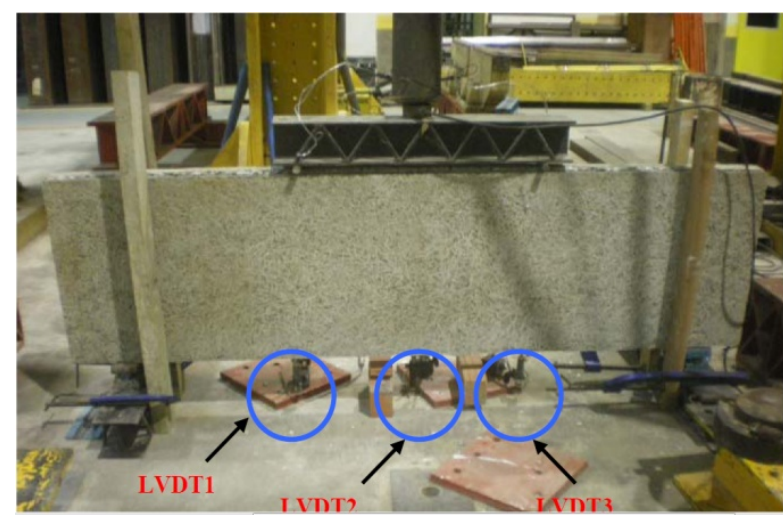

Fig. 5 The location of LVDT on WWCB wall (Aainaa 2008) 
The dimension for WWCB wall panel is as same as experimental data $600 \mathrm{~mm} \times 2000 \mathrm{~mm}$ and the thickness of the wall is $100 \mathrm{~mm}$. From the experiment the location of LVDT (Linear Vertical Displacement Transducer) on WWCB is shown in figure 5. The parameters like thickness, modulus of elasticity, poison's ratio and compressive strength are same as used in experimental result and FEA. The full nonlinear load deformation response can be seen in Figure 6. From the figure, the experimental ultimate load for wall panel can be measured was $83.03 \mathrm{KN}$ and from FEA the ultimate load is $80 \mathrm{KN}$. The maximum bending displacement was $4.89 \mathrm{~mm}$ for experimental data and $4.85 \mathrm{~mm}$ for FEA.

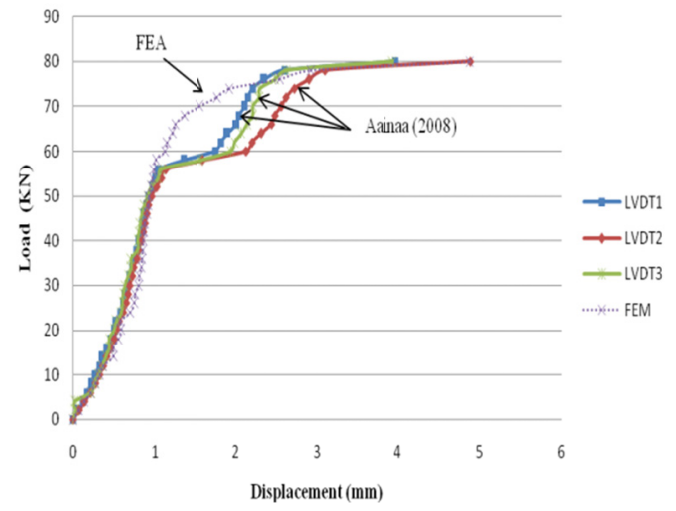

Fig.6 Load vs. Deflection curve comparison of ANSYS and Aainaa 2008

The response calculated using FEA is plotted upon the experimental response from Aainaa (2008). In the figure, FEA determined the deflection only from the centre of the panel, whereas, in the experiment it shown from three point. The entire load deformation response of the model produced compares well with the response from Aainaa (2008). This gave confidence in the use of ANSYS and the model developed.

\section{CONCLUSIONS}

A WWCB wall panel was calibrated to experimental data and prediction of deformation and flexural failure of the panel were compared to the experimental result. The failure mechanism of WWCB wall panel is modelled quite well using FEA, and the failure load predicted is very close to the failure load measured during experimental testing. From the experiment, the ultimate load for WWCB wall panel is 83.3KN. Meanwhile from the FEA the ultimate load is $80 \mathrm{KN}$. The percentage different of ultimate load between FEA and experimental data is $3.96 \%$. The comparison shows that the ANSYS finite element program is capable of modelling and predicting the actual deformation behaviour for wall panels.

\section{REFERENCES}

[1] Aainaa Shairah Bt Ahmad Shakri, MSc Thesis on Experimental Investigation Of Wood Wool Cement Board (Wwcb) Column And Load Bearing Wall Under Axial Load, Universiti Teknology Malaysia, 30April, 2008.

[2] ANSYS, “ANSYS Analysis Guide”. (2006). Ansys Inc: Canonsburg, PA15317, USA.

[3] Monique C. Hite and Harry W. Shenton, Modeling the non linear behaviour of wood frame shear walls, $15^{\text {th }}$ ASCE Engineering Mechanics Conference, June 2-5, 2002, Columbia University New York.

[4] Tavio and Tata, Predicting nonlinear behavior and stress-strain relationship of rectangular confined reinforced concrete columns with ANSYS, Civil Engineering Dimension, vol.11, No. 1, March 2009, pp. 23-31.

[5] Werasak Raongjant and Ming Jing, Finite element analysis on lightweight reinforced concriete shear walls with different web reinforcement, The sixth PSU Engineering Conference, 8-9 May, 2008.

[6] Willam, K.J. and Warnke, E.P., Constitutive model for triaxial behavior of concrete, Seminar on Structures Subjected to Triaxial Stresses, International Association of Bridge and Structural Engineering Conference, Bergamo, Italy, 1974, pp.174. 